\title{
Response of chromoblastomycosis to voriconazole
}

\author{
Alexandre Moretti de Lima ${ }^{1}$ \\ Lauren Zogbi Pereira de Paula ${ }^{1}$ \\ Hermann Soares Goetz ${ }^{2}$ \\ Pedro de Freitas Silva Torraca ${ }^{1}$
}

\author{
Gabriely Lessa Sacht ${ }^{1}$ \\ Gabriela Kimie Aseka ${ }^{1}$ \\ Maicon Felippe Gheller ${ }^{1}$
}

DOI: http:/ / dx.doi.org/10.1590/abd1806-4841.20165142

\begin{abstract}
Chromoblastomycosis is a chronic fungal infection of the epidermis, dermis and subcutaneous tissue, in which the most common etiologic agent in Brazil is Fonsecaea pedrosoi. In more advanced cases we found many difficulties in their treatment, and therefore, we report a case of extensive and severe chromoblastomycosis, with therapeutical failure of first choice treatments, but good response to voriconazole.
\end{abstract}

Keywords: Antifungal agents; Chromoblastomycosis; Fungi

Male, Caucasian, 48 years old, rural worker, after an accident with a tree branch, for the last five years has had onset of pruritus and nodular lesion on the lower left limb and lumbar region, evolving to progressive increase in erythematous verrucous plaques with areas of atrophy (Figure 1). It was then diagnosed as chromoblastomycosis by Fonsecaea pedrosoi. Since the diagnosis, during these five years the patient has undergone many treatments such as: cryosurgery; stand alone itraconazole or in combination with thermotherapy; cryosurgery and terbinafine; and itraconazole associated with terbinafine, all of them not providing apparent clinical response. In his last medical visit, patient was hospitalized and received voriconazole $200 \mathrm{mg}$ every 12 hours and, in four weeks of treatment, a significant improvement of lesions was observed, recovering movement of left knee (Figures 2, 3 and 4).

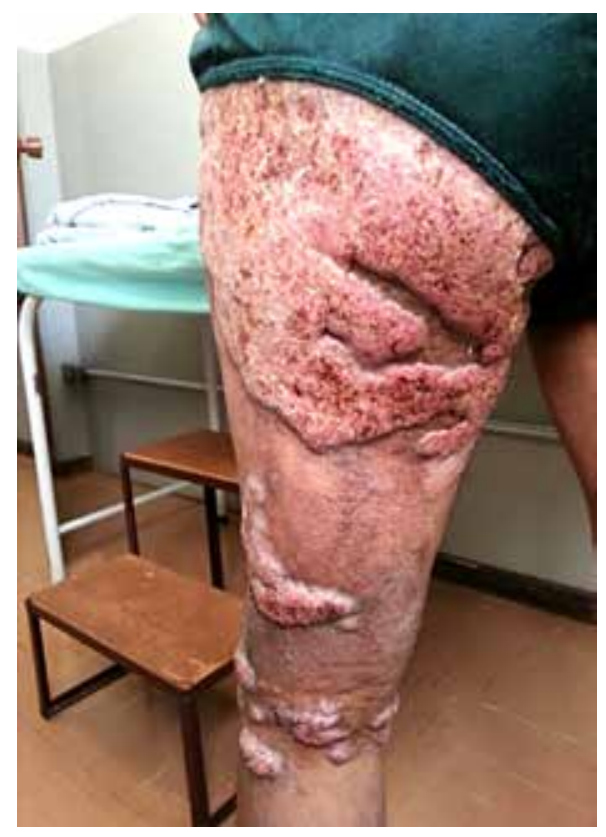

Figure 1:

Ve r r u c o u s plaques with meliceric-hematic crusts on the buttock and left lower limb

Received on 15.09.2015

Approved by the Advisory Board and accepted for publication on 16.11.2015

Work performed at Hospital Universitário Maria Aparecida Pedrossian - Universidade Federal de Mato Grosso do Sul (HUMAP-UFMS) - Campo Grande (MS), Brazil.

Financial Support: None.

Conflict of Interest: None.

Universidade Federal de Mato Grosso do Sul (UFMS) - Campo Grande (MS), Brazil.

Hospital de Doenças Tropicais de Goiás (HDT) - Goiânia (GO), Brazil.

(C2016 by Anais Brasileiros de Dermatologia 

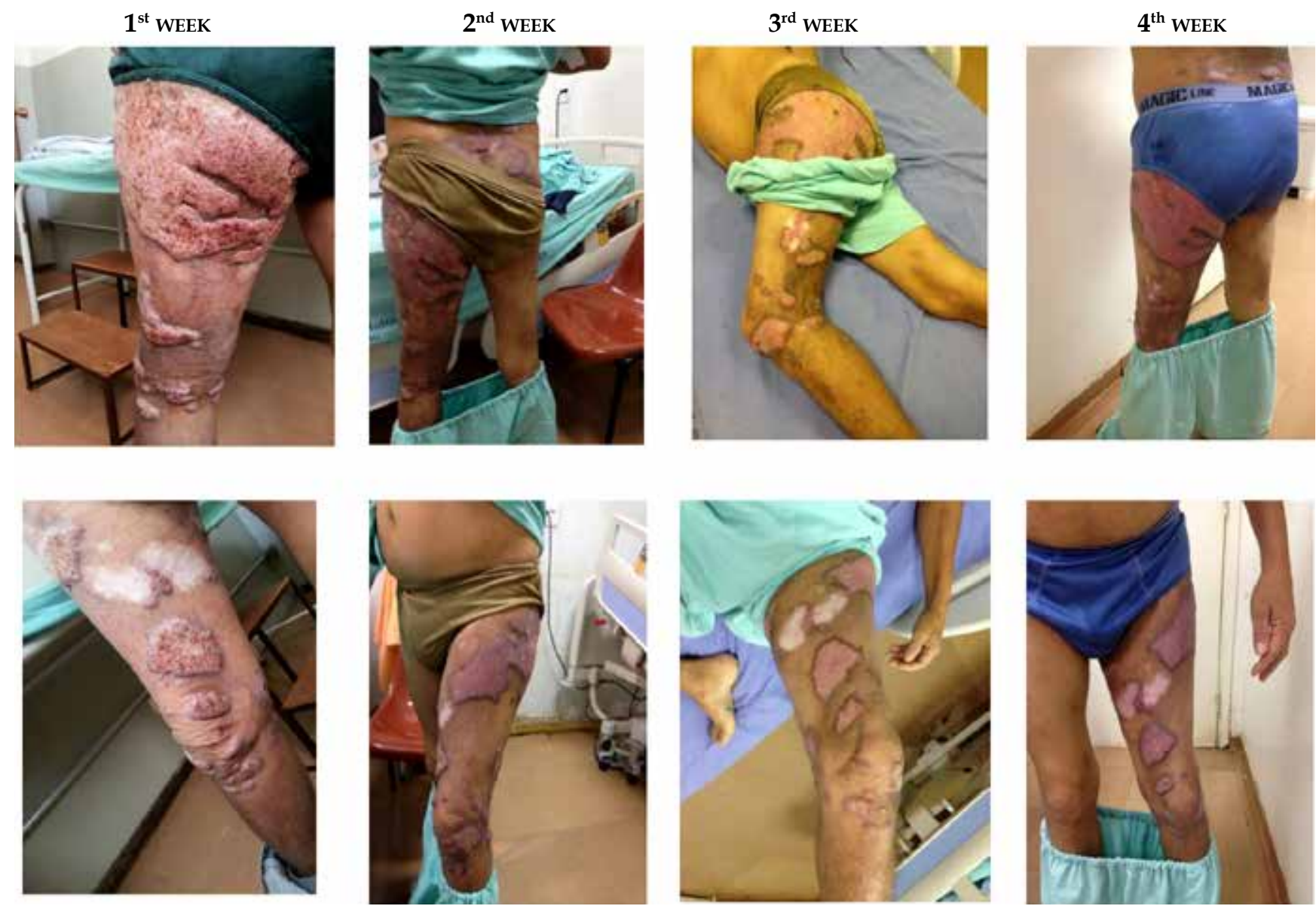

FIGURE 2: Weekly clinical evolution of verrucous lesions during 30 days of hospitalization

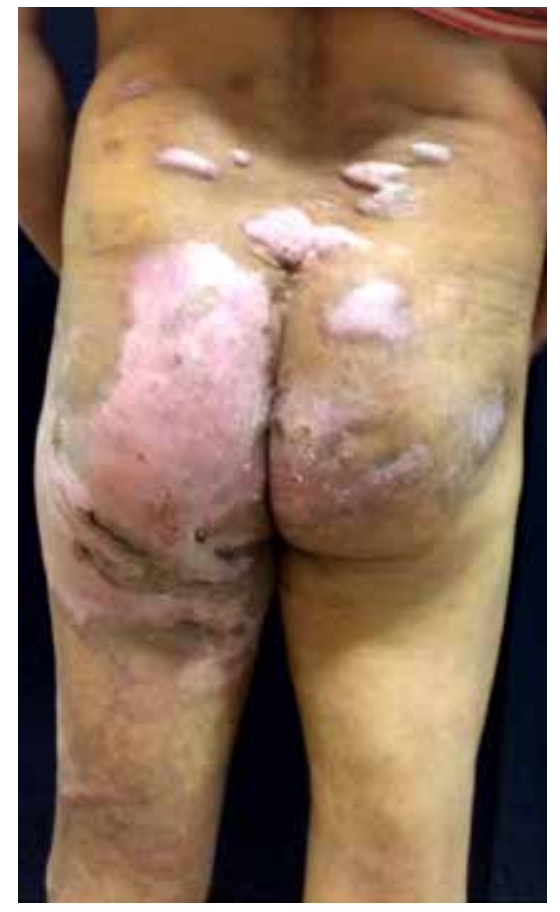

Figure 3:

Acute flattening of verrucous plaques after 12 months of treatment with voriconazole $(200 \mathrm{mg}$ orally every 12 hours).

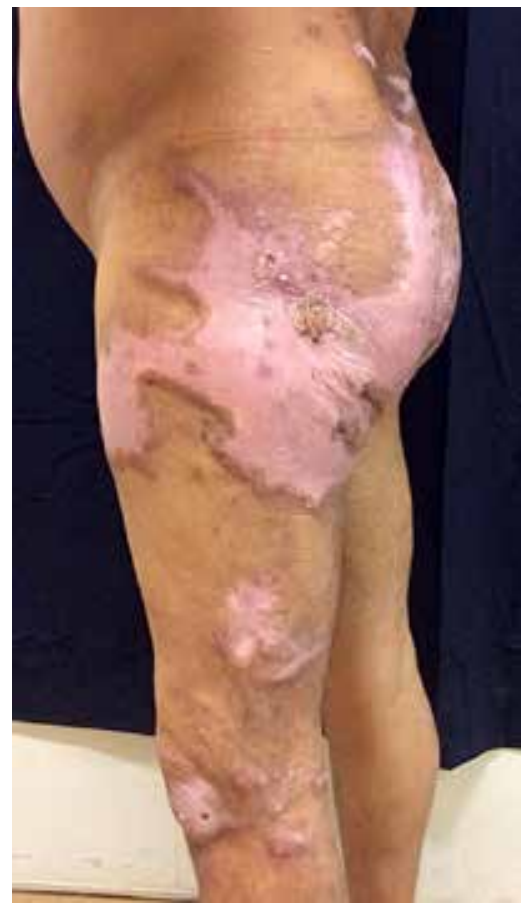

Figure 4:

Marked improvement of verrucous lesions after 12 months of treatment (side view) 


\section{DISCUSSION}

Voriconazole, a new second-generation triazole, which has been effective in cases of cerebral and disseminated phaeohyphomycosis, demonstrated activity in vitro against the main etiological agents of chromoblastomycosis, such as Fonsecaea pedrosoi, Fonsecaea monophora, Fonsecaea nubica and Cladophialophora carrionii. ${ }^{1-4}$ Similar to voriconazole, posaconazole and isavuconazole seem to be potential candidates for use in treatment of chromoblastomycosis, for they present the lowest minimal inhibitory concentrations in studies with specimens of Fonsecaea. However, only posaconazole is commercially available in Brazil since 2015. ${ }^{2,5}$ It is important to highlight the improvement of clinical conditions and quality of life of these patients, who are resistant to conventional therapeutics, with these new medications. However, clinical suspicion and early therapy in initial cases are still paramount for therapeutic success.]

\section{REFERENCES}

1. Koo S, Klompas M, Marty FM. Fonsecaea monophora cerebralphaeohyphomycosis: case report of successful surgical excision and voriconazole treatment and review. Med Mycol. 2010;48:769-74.

2. Queiroz-Telles F, Santos DW. Challenges in the Therapy of Chromoblastomycosis. Mycopathologia. 2013;175:477-88.

3. Gomes NM, Bastos TC, Cruz KS, Francesconi F. Chromoblastomycosis: an exuberant case. An Bras Dermatol. 2014;89:351-2.

4. Criado PR, Valente NY, Brandt HR, Belda Junior W, Halpern I. Dermatite verrucosa de Pedroso e Gomes (Cromomicose): 90 anos depois, ainda entre nós. An Bras Dermatol. 2010;85:104-5

5. Najafzadeh MJ, Badali H, Illnait-Zaragozi MT, De Hoog GS, Meis JF. In vitro activities of eight antifungal drugs against 55 clinical isolates of Fonsecaea spp. Antimicrob Agents Chemother. 2010;54:1636-8.
MAILING ADDRESS:

Alexandre Moretti de Lima

Av. Sen. Filinto Müller, 1

Pioneiros

79080-190 - Campo Grande, - MS

Brazil

E-mail:morettilima@yahoo.com.br

How to cite this article: Lima AM, Sacht GL, Pereira de Paula LZ, Aseka GK, Goetz HS, Gheller MF, Torraca PFS. Response of chromoblastomycosis to voriconazole. An Bras Dermatol. 2016;91(5):679-81. 